\title{
EL ARCHIVO FOTOGRÁFICO DEL ARQUITECTO EMILIO PÉREZ PIÑERO. ESTRUCTURA Y ANÁLISIS DOCUMENTAL
}

\author{
María Carmen Pérez Almagro* \\ Fundación Emilio Pérez Piñero (Murcia).
}

\begin{abstract}
Resumen: Esta investigación ha consistido en el análisis, descripción e interpretación de la documentación fotográfica relacionada con el arquitecto Emilio Pérez Piñero. Tras un proceso de recopilación documental, se ha realizado una propuesta de cuadro de clasificación, dedicando una sección del fondo Emilio Pérez Piñero a Archivo Fotográfico; se han definido los descriptores más comunes y se ha creado una ficha documental tipo, conforme a las reglas actuales de archivística. El objetivo de este artículo es dar a conocer la estructura y el contenido del archivo fotográfico, como una puesta más en valor de la figura y obra del arquitecto como generador y difusor de imágenes. Palabras clave: análisis documental; archivo fotográfico; arquitecto Emilio Pérez Piñero; arquitectura transformable; cuadro de clasificación; DOMUS; ficha documental; fondo documental; ISAD (G); Ministerio de Información y Turismo; propaganda política; Salvador Dalí.

Title: THE PHOTOGRAPHIC FILE OF ARCHITECT EMILIO PÉREZ PIÑERO. STRUCTURE AND DOCUMENTARY ANALYSIS.

Abstract: This research has consisted in the analysis, description and interpretation of the photographic documentation related to the architect Emilio Pérez Piñero. After a process of documentary compilation, ithas made a proposal of classification table, dedicating a section of the Emilio Pérez Piñero's fund to the Photographic Archive; also it has defined the most common descriptors and has created a type of documentary file, according to the current archival rules. The objective of this article is to make known the structure and the content of the photographic archive, putting in value the figure and work of the architect like generator and diffuser of images.

Keywords: documentary analysis; photographic file; architect Emilio Pérez Piñero; transformable architecture; classification table; DOMUS; documentary file; documentary fond; ISAD (G); Ministry of Information and Tourism; political propaganda; Salvador Dalí.
\end{abstract}

Copyright: (C 2017 Servicio de Publicaciones de la Universidad de Murcia (Spain). Este es un artículo de acceso abierto distribuido bajo los términos de la licencia Creative Commons Reconocimiento 4.0 Internacional (CC BY 4.0).

\section{INTRODUCCIÓN}

La protección jurídica del patrimonio fotográfico se remonta a la década de los ochenta del siglo pasado. Con la promulgación de la Ley 16/1985, de 25 de junio, de Patrimonio Histórico Español se empezó a tener mayor conciencia sobre este patrimonio. Se entiende por documento... toda expresión en lenguaje natural o convencional y cualquier otra expresión gráfica, sonora o en imagen, recogida en cualquier tipo de soporte material, incluso los soportes informáticos... (Art. 49.1). Otro hito en este camino de preservación son las I Jornadas para la Conservación y Recuperación de la Fotografia (1985).

La Ley de Propiedad Intelectual, $R$. D. 1/1996, de 12 de abril, considera la fotografía una obra de creación intelectual y por tanto se protegen los derechos de autor. Recientemente, el Instituto del Patrimonio Cultural de España ha creado el Plan Nacional de Conservación del Patrimonio Fotográfico (2015), donde se desarrollan los criterios y metodología para proteger, conservar y difundir este legado.

Como complemento a la protección jurídica está la normativa documental, siendo uno de sus fines gestionar la información de interés científico e histórico de los diferentes fondos museográficos, documentales (imágenes), administrativos y bibliográficos (Carretero Pérez et al., 1996). Al no existir una única regla estandarizada definida para clasificar el patrimonio fotográfico, en el caso del archivo de la Fundación Emilio Pérez Piñero se ha optado por el Sistema Integrado de Documentación y Gestión Museográfica (DOMUS) desarrollado por el Ministerio de Cultura y la General International Standard Archival Description (ISAD (G)) publicada por el Consejo Internacional de Archivos.

*archivo.fundacion@perezpinero.org

Recibido: 14-12-2016; 2ª versión: 14-03-2017; 3ª versión: 28-03-2017; aceptado: 04-04-2017.

PÉREZ ALMAGRO, M.C. El archivo fotográfico del arquitecto Emilio Pérez Piñero. Estructura y análisis documental. Anales de Documentación, 2017, vol. 20, nº 2. Disponible en: http://dx.doi.org/10.6018/analesdoc.20.2.277831. 
Emilio Pérez Piñero (Valencia, 1935 - Castellón, 1972) fue un arquitecto español del siglo XX que vivió y desarrolló su profesión en Calasparra (Murcia) de donde era originaria su familia. Estudió en la Escuela Superior de Arquitectura de Madrid y cuando aún era estudiante de cuarto curso recibió el primer galardón por su singular estructura Teatro Ambulante Desplegable en el VI Congreso de la Unión Internacional de Arquitectos (Londres, 1961).

En sus inicios, su trayectoria profesional y personal estuvo marcada por fuertes penurias económicas. De ahí que sus investigaciones se caracterizasen por economizar en medios y tiempo, alcanzar la sostenibilidad y reutilizar materiales; de modo que empleó partes de sus propios prototipos, para construir otros diseños más avanzados y novedosos. En la década que ejerció la profesión innovó en más de veinte soluciones experimentales como teatros ambulantes, pabellones para exposiciones, salas de cine, pistas polideportivas, invernaderos y cubiertas arquitectónicas. Construyó cinco obras mediante encargo público y privado y patentó cuatro estructuras a nivel internacional.

Un episodio a destacar dentro de la carrera de Pérez Piñero fue el interés que despertaron sus estructuras para el gobierno norteamericano. A finales de los años 60 y principios de los 70, la NAVY quiso adaptar una de las patentes del arquitecto para realizar un pabellón que cubriera sus necesidades en la base militar de la Antártida (serie fotográfica 17: Carpa Desplegable, 1969-70). El otro proyecto corresponde a la NASA. La agencia espacial pretendía instalar un invernadero en la luna para experimentos científicos (serie fotográfica 16: Módulo desplegable automático, 1969). Sin embargo, la distancia entre la administración americana y Pérez Piñero, la lentitud de las comunicaciones y otras cuestiones sobrevenidas malograron estos proyectos. Al mismo tiempo, Salvador Dalí vio numerosas posibilidades en estas estructuras para materializar sus sueños más surrealistas, por ello le encargó la cúpula que corona su teatro-museo de Figueres (Girona) y la Vidriera Hipercúbica.

Pérez Piñero contribuyó a la Arquitectura con su capacidad inventiva desarrollando propuestas vanguardistas de estructuras desplegables y modulares. En reconocimiento a sus investigaciones recibió numerosos galardones, entre los que destaca el premio Auguste Perret de 1972 concedido por la Unión Internacional de Arquitectos (Pérez Almagro, 2017).

Este trabajo sobre la documentación fotográfica conocida de Pérez Piñero se engloba en una investigación holística de la vida y obra del arquitecto a través de su legado cultural, que la autora de este artículo realiza en la Fundación homónima.

El archivo de la Fundación Emilio Pérez Piñero está constituido por fondos de diferentes personalidades, siendo el principal el dedicado a Emilio Pérez Piñero:

- Fondo Emilio Pérez Piñero (FEPP): 1935-1972

- Fondo Antonio Pérez Ruiz (FAPR): 1901-1969

- Fondo José María Pérez Piñero (FJMPP): 1933-2010

- Fondo Félix Candela (FFCA): 1968-1997

- Fondo Emilio Pérez Belda (FEPB): 1992-hasta el presente

Este legado está compuesto por documentos personales y profesionales del arquitecto depositados en la fundación privada que su familia constituyó en 1992 como conmemoración del vigésimo aniversario de su fallecimiento.

El objetivo de este trabajo ha sido dar a conocer la estructura y contenido del fondo Emilio Pérez Piñero (Tabla I), para ello se ha empleado una metodología de tipo cuanti-cualitativa, con trabajo de campo en el propio archivo de la Fundación, así como en otras instituciones que están vinculadas al arquitecto. Se ha realizado el análisis, clasificación, interpretación y digitalización de las diferentes colecciones fotográficas que componen su obra. Tras la cuantificación de las imágenes, en su mayoría positivos y negativos, se ha elaborado una ficha documental tipo en base a la normativa vigente en archivística (Tablas II y III). Para contextualizar la investigación se ha revisado la bibliografía sobre gestión de fondos y sistematización de colecciones fotográficas, así como las referencias contemporáneas de archivos fotográficos de arquitectura.

¿Por qué Pérez Piñero hizo o encargó realizar más de tres mil fotografías de su obra en la década que ejerció la profesión?, ¿qué finalidad tenían esas imágenes? El arquitecto tuvo que enfrentarse a dos condicionantes propios de la época: los escasos estudios referidos a estructuras y la inexistencia de un modelo de cálculo afinado del funcionamiento estructural aplicable a sus diseños. Además, a estos condicionantes se sumaba la dificultad técnica de plasmar el proceso, por ello el arquitecto no siempre dibujó todos los sistemas en planos y prefirió recurrir a la 
construcción de modelos a escala con el fin de experimentar sus ideas. Su metodología de trabajo se iniciaba con la aproximación geométrica de la forma, la realización del proyecto y finalmente la toma de series fotográficas. En otros casos, cuando terminaba de construir el modelo, una vez comprobado su funcionamiento lo desmontaba para reutilizar algunas de las piezas en la nueva construcción. Este es el motivo fundamental por el cual hay ausencias de maquetas o modelos y de que solo se conozcan estas estructuras transformables y modulares, ya inexistentes, a través de comentarios, reflexiones manuscritas, incipientes bocetos y, sobre todo, fotografías.

\section{ESTRUCTURA Y CONTENIDO DEL ARCHIVO}

Por lo general, los archivos profesionales privados de arquitectos aplican sus propias normas para clasificar los diferentes expedientes, escritos, proyectos, informes, planos, croquis o fotografías (Rivas Quinzaños y otros, 2011). En cambio, la colección monográfica de Pérez Piñero se ha estructurado bajo los estándares de la archivística actual.

Para el archivo de la Fundación era una necesidad planificar y organizar el contenido de la sección Archivo Fotográfico del Fondo Emilio Pérez Piñero desde la óptica histórico-documental. La primera de las disciplinas ha sido el eje espacio-temporal en el proceso de recopilación y análisis de las series. La segunda perspectiva ha consistido en la clasificación, ordenación y normalización sistemática de los documentos fotográficos.

La colección monográfica del arquitecto está constituida por fondos museográficos (maquetas, modelos y estructuras) y documentales generados por él e intrínsecamente relacionados. Se divide en seis secciones (Tabla I) que a su vez están formadas por varias series ordenadas cronológicamente. La mayoría de los expedientes están fechados entre 1961-1972, contexto que enmarca la década en que el arquitecto ejerció la profesión (Pérez Almagro, 2013, p. 497-667).

Fondo Emilio Pérez Piñero

1. Documentos personales

1.1. Biografía y currículum

1.2. Correspondencia familiar y personal

1.3. Correspondencia Félix Candela

1.4. Apuntes de la Escuela Superior de Arquitectura de Madrid

1.5. Reconocimientos, premios y galardones

1.6. Obra artística

1.7. Objetos varios

2. Proyectos experimentales y no construidos

2.1. Teatro Ambulante Desplegable UIA (1961)

2.2. Proyecto Fin de Carrera (1962)

2.3. Ermita de la Estación (1962)

2.4. Cúpula Rebajada Desplegable (1962)

2.5. Teatro Ambulante Desplegable (1963)

2.6. Cúpula reticular poliédrica (1965)

2.7. Cúpula reticular desplegable o cúpula reticular transportable y desplegable desde un helicóptero (1962 y 1966)

2.8. Cúpula reticular desplegable para grandes luces (1968)

2.9. Propuestas para Pabellón en la Antártida (1969-1970)

2.10. Maqueta Módulo lunar (1969)

2.11. Propuestas para sala de cine-teatro en Libia(1968)

2.12. Polideportivo en Camerún (1969-1970)

2.13. Propuestas para pistas polideportivas (1970)

2.14. Soluciones cupulares para invernaderos (1970)

2.15. Maqueta de cubierta para plaza de toros de Campo Pequeno de Lisboa (1971)

2.16. Maqueta de Vidriera Hipercúbica para el Teatro-Museo Dalí (1971)

2.17. Cúpulas-diamantes erizos de mar neoplatónicos en Ampuria Brava (1971)

2.18. Anteproyecto de cubierta para el Velódromo de Anoeta de San Sebastián (1971)

3. Proyectos realizados

3.1. Pabellón Transportable para Exposición XXV Años de Paz (1964)

3.2. Teatro Transportable para Festivales de España (1966) 
3.3. Estructura para sala de proyecciones mediante sistema Cinerama (1967)

3.4. Fila de Butacas desplegables (1967)

3.5. Arquitectura Tradicional (1966-1972)

3.6. Cúpula Teatro-Museo Dalí (1969-1973)

3.7. Cubiertas Necrópolis Paleocristiana de Tarragona (1970-1973)

4. Hemeroteca

4.1. Publicaciones y prensa

4.2. Archivo de voz y palabra

4.3. Archivo audiovisual

5. Archivo fotográfico

5.1. Estructura reticular estérea plegable (1961)

5.2. Cúpula rebajada desplegable (1962)

5.3. Proyecto Fin de Carrera (1962)

5.4. Maqueta de la Ermita de la Estación (1963)

5.5. Pabellón Transportable para Exposiciones (1964)

5.6. Estructura reticular desplegable plana (base de la maqueta Vidriera Hipercúbica, 1964)

5.7. Estructura desplegable plana (1964)

5.8. Cúpula reticular desplegable (1962)

5.9. Cúpula reticular poliédrica desmontable (1965-1966)

5.10. Teatro Transportable para Festivales de España (1966)

5.11. Fila de butacas plegable (1966-1967)

5.12. Cúpula reticular transportable y desplegable desde un helicóptero (1966)

5.13. Estructura para la sala de proyecciones mediante sistema Cinerama (1967)

5.14. Cúpula reticular desmontable de chapa (1967)

5.15. Cúpula desplegable para grandes luces (1968)

5.16. Módulo desplegable automático (1969)

5.17. Carpa desplegable (1970)

5.18. Cúpula reticular poliédrica F-12 (1969-1973)

5.19. Vidriera Hipercúbica (1971)

5.20. Cubiertas Museo Paleocristiano de Tarragona (1970-1973)

5.21. Cubierta Velódromo de Anoeta (1971)

5.22. Fotografías personales de Emilio Pérez Piñero

5.23. Fotografías personales de Félix Candela

5.24. Fotografías de la Exposición de la Fundación

6. Planos

6.1. Estructura reticular estérea plegable (1961)

6.2. Cúpula rebajada desplegable (1962)

6.3. Vivienda de sacerdote (1962)

6.4. Proyecto Fin de Carrera (1962)

6.5. Maqueta Ermita de la Estación (1963)

6.6. Teatro Ambulante (1963)

6.7. Pabellón Transportable para Exposiciones (1964)

6.8. Teatro Transportable para Festivales de España (1966)

6.9. Estructura para sala de proyecciones mediante sistema Cinerama (1967)

6.10. Salas de cine-teatro en Libia (1968)

6.11. Polideportivo en Camerún (1970)

6.12. Cúpula reticular poliédrica F-12 (1969-1973)

6.13. Vidriera Hipercúbica (1971)

6.14. Cubierta Museo Paleocristiano de Tarragona (1970-1973)

6.15. Cubierta Velódromo de Anoeta (1971)

Tabla I. Cuadro de clasificación. Secciones del Fondo Emilio Pérez Piñero.

Aunque la inmensa mayoría de los fondos documentales fotográficos se encuentran en la Fundación, en calidad de depósito, se ha realizado una labor de recopilación e investigación de material gráfico en las instituciones que están vinculadas con el arquitecto, por custodiar expedientes, realizar estudios, encargos de proyecto, etc.: 
- Airbus Military EADS y Servicio Histórico y Cultural del Ejército del Aire (Madrid)

- Archivo Almudí (Murcia)

- Archivo General de la Administración (Madrid)

- Archivo Municipal de Donostia (San Sebastián)

- Arxiu Municipal de L'Hospitalet de Llobregat (Barcelona)

- Centre d'Estudis Dalinians de la Fundación Gala-Salvador Dalí (Girona)

- Ciudad de los Muchachos de Benposta (Ourense)

- Colegio Oficial de Arquitectos de Murcia (Murcia)

- Escuela Técnica Superior de Arquitectura de Madrid (Madrid)

- Museu Nacional Arqueològic de Tarragona (Tarragona)

- Vicerrectorado de Extensión Universitaria y Relaciones Institucionales de la Universidad de Alcalá de Henares (Madrid)

La sección documental quinta (S5) del Fondo Emilio Pérez Piñero, denominada Archivo Fotográfico, está formada por 1244 negativos y 1957 positivos, cuya temática es el desarrollo profesional del arquitecto. La S5 se estructura en veintiuna series fotográficas de cada uno de los proyectos del arquitecto (experimentales o realizados). Se trata de imágenes en blanco y negro y soporte analógico, en mayor medida en papel y plástico, pero también hay diapositivas y vidrio. En este proceso de investigación, se ha analizado qué documentos fueron realizados y revelados por el propio arquitecto (Figura 1) y en cuales contó con la colaboración de los estudios locales de Calasparra. La contribución más notable fue realizada por el estudio Fotos García, perteneciente a Pascual García y Avelina Moreno.

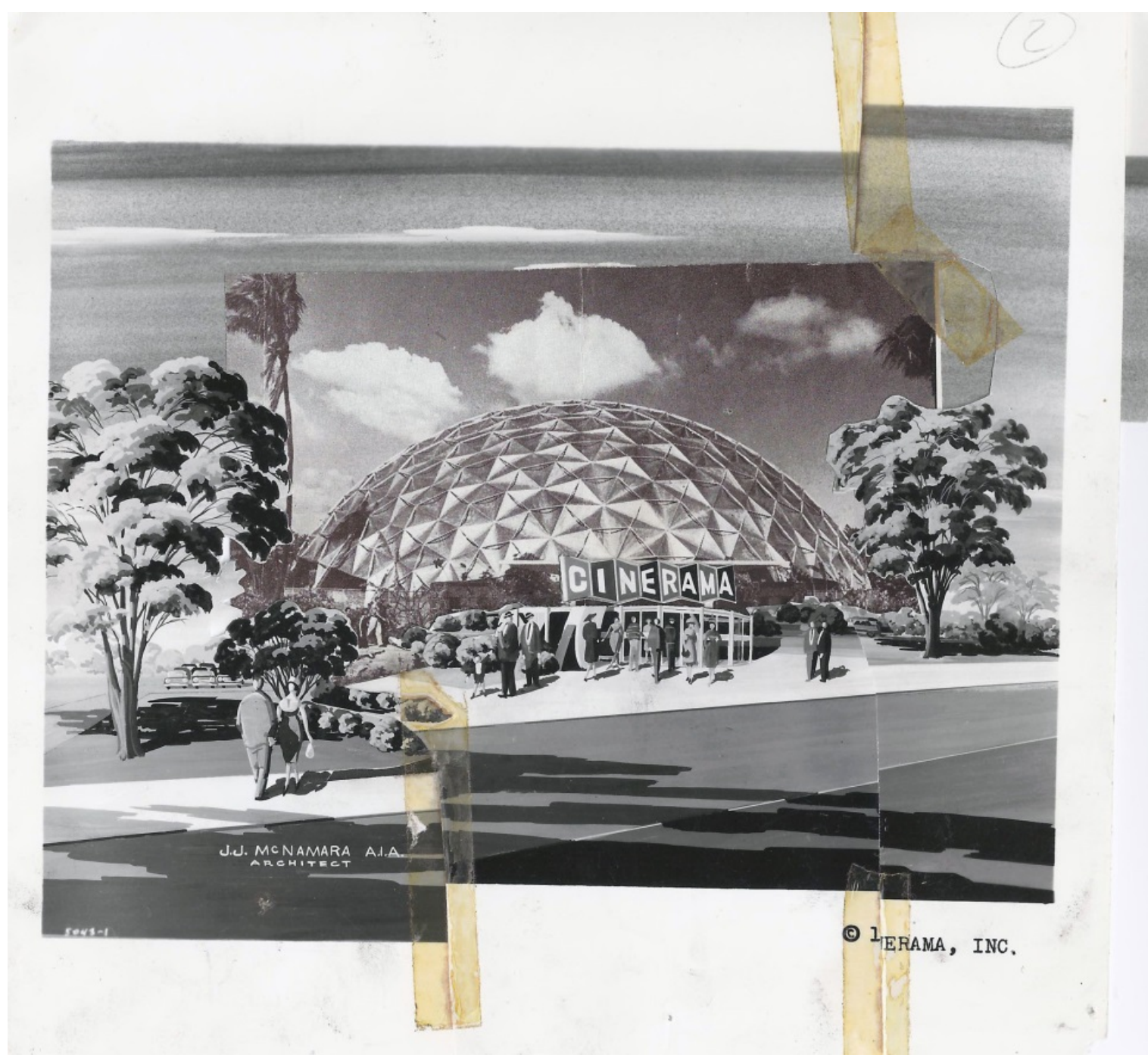

Figura 1. Fotomontaje realizado por Pérez Piñero para un proyecto de sala de cine (1967). ${ }^{\odot}$ Fundación Emilio Pérez Piñero. 
Otras aportaciones son las llevadas a cabo por los fotógrafos oficiales que trabajaban para el gobierno central. Es decir, cuando la Administración encargaba a Pérez Piñero una obra, la institución competente enviaba un fotógrafo al lugar para que tomara varias secuencias del proceso de montaje, fundamentalmente del momento de la inauguración. Con esta actuación, los avances técnicos alcanzados por el arquitecto sirvieron también al gobierno de la época como un instrumento más de propaganda política para presentar una imagen nueva y moderna del país. Así lo expresaba Carlos Robles Piquer, Director General de Información y Turismo entre 1962-67, en una entrevista realizada por la Fundación Emilio Pérez Piñero en 2011:

La pérdida de Emilio fue una pérdida grave para este país. Un hombre que empezaba todavía como joven que era, lo que habría podido contribuir al desarrollo de nuestra técnica, de nuestro arte, de la construcción del mundo del espectáculo. (AFEPP, FEPP. Sección Hemeroteca: Archivo de voz y palabra).

Otra aportación que conviene destacar fue la labor de los fotógrafos de Salvador Dalí: Meli para las imágenes de la provincia de Girona (Cúpula reticular poliédrica F-12 del Teatro-Museo de Dalí) y Marc Lacroix como fotógrafo oficial del pintor en sus viajes (Vidriera Hipercúbica). En el caso de estos encargos, la Fundación sólo dispone de los positivos de las fotografías.

Para la descripción completa del fondo se ha empleado la norma ISAD (G) que posibilita la descripción multinivel de todas las partes que lo componen empleando elementos apropiados para cada unidad de descripción estructurada jerárquicamente. Paralelamente se ha llevado a cabo un proceso de inventario, catalogación y digitalización de las imágenes en formato JPG y TIFF y se han definido los tesauros y descriptores más habituales de las series (Tabla II).

\begin{tabular}{|c|c|}
\hline Campos & - $\quad$ Códigos/Tesauros/Descriptores \\
\hline Inventario & $\begin{array}{ll}\text { - ES_FEPP_S5_CVD_S1_001 } \\
\text { - ES: código internacional 'España' } \\
\text { - } \quad \text { FEPP: código 'Fundación Emilio Pérez } \\
\text { Piñero'/'Fondo Emilio Pérez Piñero' } \\
\text { - S5: abreviatura 'Sección 5' } \\
\text { - CVD: ejemplo de abreviatura individual de cada } \\
\text { - } \\
\text { serie: "Colección Vidriera Dali'" } \\
\text { - } \quad N^{\circ} \text { currens con tres dígitos }\end{array}$ \\
\hline Ubicación & Fundación Emilio Pérez Piñero \\
\hline Clasificación genérica & $\begin{array}{ll}\text { - } & \text { Actividades profesionales } \\
\text { - } & \text { Arquitectura } \\
\text { - } & \text { Fotografía } \\
\text { - } & \text { Proyecto realizado } \\
\text { - } & \text { Proyecto experimental y no construido } \\
\text { - } & \text { Retrato }\end{array}$ \\
\hline Objeto/Documento & $\begin{array}{l}\text { Negativo } \\
\text { Positivo }\end{array}$ \\
\hline \multicolumn{2}{|l|}{ Título } \\
\hline Autor & $\begin{array}{ll}\text { - } & \text { Antonio Cores } \\
\text { - } & \text { Company } \\
\text { - } & \text { Emilio Pérez Piñero } \\
\text { - } & \text { Fotos García } \\
\text { - } & \text { Hermes } \\
\text { - } & \text { Josep Bonastre } \\
\text { - } & \text { Juan Ciuret } \\
\text { - } & \text { Marc Lacroix } \\
\text { - } & \text { Meli (Melitón Casals Casas) } \\
\text { - } & \text { Nico } \\
\text { - } & \text { Paisajes Españoles } \\
\end{array}$ \\
\hline - $\quad$ Soporte & $\begin{array}{ll}\text { - } & \text { Diapositiva } \\
\text { - } & \text { Papel } \\
\text { - } & \text { Plástico } \\
\text { - } & \text { Vidrio }\end{array}$ \\
\hline Técnica & Blanco y negro \\
\hline
\end{tabular}




\begin{tabular}{|c|c|}
\hline & Color \\
\hline Dimensiones/Formato & $\begin{array}{ll} & \text { Formato medio }(6 \times 6 \mathrm{~cm} ; 9 \times 12 \mathrm{~cm} ; 18 \times 13 \\
& \mathrm{cm}) \\
- & \text { Gran formato } \\
- & \text { Paso universal }(35 \mathrm{~mm})\end{array}$ \\
\hline Descripción & Punto de vista formal \\
\hline Descriptores & $\begin{array}{l}\text { Sujetos representados } \\
\text { Retrato }\end{array}$ \\
\hline Contexto cultural & Contemporáneo. Tercer cuarto del siglo XX \\
\hline Datación & Fechas comprendidas entre $1935-1972$ \\
\hline Procedencia & $\begin{array}{l}\text { Estudio fotográfico... } \\
\text { Emilio Pérez Piñero }\end{array}$ \\
\hline \multicolumn{2}{|l|}{ Lugar de producción } \\
\hline Uso/Función & $\begin{array}{ll}\text { - } & \text { Artístico } \\
\text { - } & \text { Informativo } \\
\text { - } & \text { Publicitario } \\
\text { - } & \text { Registro } \\
\end{array}$ \\
\hline Clasificación razonada & $\begin{array}{l}\text { Historia de la fotografía, el porqué del proyecto, otra } \\
\text { información de interés }\end{array}$ \\
\hline Bibliografía & Publicaciones relacionadas \\
\hline Tipo de colección & $\begin{array}{l}\text { Asignado } \\
\text { Depósito }\end{array}$ \\
\hline Forma de ingreso & $\begin{array}{l}\text { Asignación } \\
\text { Depositado } \\
\text { Legado }\end{array}$ \\
\hline Observaciones & Relación fondos documentales y museográficos \\
\hline \multicolumn{2}{|l|}{ Catalogador } \\
\hline \multicolumn{2}{|l|}{ Cumplimentador } \\
\hline Estado de conservación & Bueno \\
\hline
\end{tabular}

Tabla II. Campos y términos más comunes de la sección Archivo Fotográfico del fondo Emilio Pérez Piñero.

Con el análisis, clasificación y catalogación documental se ha pretendido conservar y difundir la información de los documentos a partir de los criterios actuales de la archivística. Para la descripción en profundidad de cada unidad documental, desde la Fundación Emilio Pérez Piñero se ha diseñado una propuesta de ficha documental (Tabla III) con campos comunes a DOMUS e ISAD $(\mathrm{G})$ que agrupa la siguiente información:

a) Identificación: inventario, ubicación.

b) Clasificación: clasificación genérica, objeto, título, autor, soporte, técnica, dimensiones.

c) Descripción, análisis e interpretación: descripción, descriptores, contexto cultural, datación, procedencia, uso/función, clasificación razonada, bibliografía, estado de conservación.

d) Datos administrativos: tipo de colección, forma de ingreso, fecha de ingreso, observaciones, catalogador, cumplimentador.

\begin{tabular}{|l|l|l|}
\hline Inventario & ES_FEPP_S5_CVD_S1_001 & \\
& & \\
\hline Ubicación & & \\
\hline Clasificación Genérica & Fotografia & \\
\hline
\end{tabular}




\begin{tabular}{|c|c|}
\hline & Proyecto experimental y no construido \\
\hline Objeto & Fotografía \\
\hline Título & Dalí y Pérez Piñero con la Vidriera Hipercúbica debajo de la Torre Eiffel \\
\hline Autor & Marc Lacroix \\
\hline Soporte & Papel \\
\hline Técnica & Blanco y negro \\
\hline Dimensiones & $24 \times 18 \mathrm{~cm}$ \\
\hline Descripción & $\begin{array}{l}\text { Fotografía en blanco y negro, formato vertical. La imagen presenta a dos } \\
\text { hombres posando en plano americano o tres cuartos, uno frente al otro, debajo } \\
\text { del monumento Torre Eiffel. En el centro de la fotografía hay una estructura } \\
\text { metálica y de vidrio desplegada. A la izquierda aparece Salvador Dalí vestido } \\
\text { con traje oscuro y abrigo de piel. Tiene el brazo derecho doblado a la altura del } \\
\text { pecho, con la mano cerrada apuntando con el dedo índice hacia la estructura } \\
\text { metálica. El brazo izquierdo lo apoya al cuerpo con la mano cerrada mientras } \\
\text { sostiene un bastón. A la derecha de la imagen está Emilio Pérez Piñero vestido } \\
\text { con traje oscuro y mirando a Dalí. Tiene el brazo derecho junto al cuerpo, a la } \\
\text { altura del vientre, con la mano abierta. }\end{array}$ \\
\hline Descriptores & Emilio Pérez Piñero. Retrato. Salvador Dalí. Torre Eiffel \\
\hline Contexto Cultural & Contemporáneo. Tercer cuarto del siglo XX \\
\hline Datación & $1971 / 12$ \\
\hline Procedencia & Marc Lacroix \\
\hline Uso/Función & Informativo. Publicitario \\
\hline Clasificación razonada & $\begin{array}{l}\text { - La Vidriera Hipercúbica, con el nombre técnico de "Sistema de planos } \\
\text { articulados cubriendo una estructura reticular estérea desplegable", fue un } \\
\text { encargo de Dalí a Pérez Piñero para cerrar la embocadura del escenario del } \\
\text { Teatro-Museo Dalí de Figueres (Girona). } \\
\text { - Está diseñada para portar ochenta y cuatro vidrieras cuadradas. El resultado de } \\
\text { todo el conjunto plegado es una forma cúbica en el centro del espacio a cubrir, } \\
\text { que una vez desplegada lo cerraba por las zonas de la cruz fija. Las vidrieras se } \\
\text { despliegan automáticamente mediante un sistema hidráulico, surgiendo unas } \\
\text { detrás de otras hasta crear una superficie totalmente plana. } \\
\text { El pintor pensaba crear figuras y efectos que pasarían por infinitas posiciones } \\
\text { intermedias con imágenes cambiantes de superposiciones de los planos } \\
\text { translúcidos, al modo de la rueda cinética de Raimundo Lulio. La temática sería } \\
\text { "La Santísima Trinidad". } \\
\text { En noviembre de } 1971 \text { el arquitecto realizó esta estructura y a principios de } \\
\text { diciembre Dalí y Pérez Piñero la presentaron en París, ante los medios de } \\
\text { comunicación. En este caso fue fotografiada por Marc Lacroix debajo de la Torre } \\
\text { Eiffel y delante de la fachada principal de la catedral de Nôtre Dame. } \\
\text { En 1964, Pérez Piñero había realizado una maqueta denominada "Estructura } \\
\text { reticular desplegable plana". A partir de esta estructura, el arquitecto preveía su } \\
\text { aplicación como antenas captadoras de energía en satélites artificiales. Se trataba } \\
\text { de la base que más tarde empleó en este proyecto. } \\
\text { Patente de invención no 397.963, "Sistema de planos articulados cubriendo una } \\
\text { estructura reticular estérea desplegable", Madrid, 29-04-1972. Solicitud de } \\
\text { continuación en parte en Estados Unidos de América no 546.634, "Sistema de } \\
\text { planos articulados cubriendo una estructura reticular estérea". Esta última patente } \\
\text { la realizan los Herederos de Pérez Piñero en Madrid, 10-10-1975. }\end{array}$ \\
\hline Bibliografía & $\begin{array}{l}\text { - DALÍ, S. 1972. "Sobre la obra de Emilio Pérez Piñero. El pensamiento de } \\
\text { Salvador Dalí", Arquitectura, no 163-164, julio-agosto, Madrid, p. 5-8. } \\
\text { - } \quad \text { DE MIGUEL, C. 1972. "Emilio Pérez Piñero 1935-1972", L'Architecture } \\
\text { d'Aujourd'hui, no 164, octubre-noviembre, p. 5. } \\
\text { - ESCRIG, F. 1993. "Las estructuras de Emilio Pérez Piñero", Arquitectura } \\
\text { Transformable, Sevilla, Textos de Arquitectura, Publicación de la Escuela } \\
\text { Técnica Superior de Arquitectura de Sevilla, p. 11-32. } \\
\text { - PÉREZ PIÑERO, E. 1972. "Emilio Pérez Piñero, Premio Auguste Perret", } \\
\text { Arquitectura, no 163-164, julio-agosto, Madrid, p. 23-24. } \\
\text { - } \quad \text { PÉREZ VALCÁRCEL, J.B. y ESCRIG, J.F. 1992. "La obra arquitectónica de }\end{array}$ \\
\hline
\end{tabular}




\begin{tabular}{|c|c|}
\hline & $\begin{array}{l}\text { Emilio Pérez Piñero", Boletín Académico. Escuela Técnica Superior de } \\
\text { Arquitectura, A Coruña, no 16, p. 3-12. } \\
\text { - PUERTAS DEL RÍO, L. 1989. Estructuras desmontables y desplegables. } \\
\text { Estudio de la obra del arquitecto Emilio Pérez Piñero, Madrid, Escuela Técnica } \\
\text { Superior de Arquitectura de la Universidad Politécnica de Madrid, Tesis doctoral } \\
\text { inédita, p. 62-63. }\end{array}$ \\
\hline Tipo de Colección & Depósito Herederos Pérez Piñero \\
\hline Forma de Ingreso & Legado \\
\hline Fecha de ingreso & 1992 \\
\hline Observaciones & $\begin{array}{ll} & \text { Serie 2. Proyectos experimentales y no construidos: } \\
\text { - } & \text { ES_FEPP_S2_01_016_00001 a ES_FEPP_S2_01_016_00026. } \\
\text { - } & \text { Archivo fotográfico. Colección 6. Subserie 1: } \\
\text { - } & \text { ES_FEPP_S5_CERDP_S1_00001 a ES_FEPP_S5_CERDP_S1_00019. } \\
\text { - } & \text { Archivo fotográfico. Colección 7. Subserie 1: } \\
\text { - } & \text { ES_FEPP_S5_CEDP_S1_00001 a ES_FEPP_S5_CEDP_S1_00027. } \\
\text { - } & \text { Archivo fotográfico. Colección 19. Subserie 1: } \\
\text { - ES_FEPP_S5_CVD_S1_00001 a ES_FEPP_S5_CVD_S1_00003. } \\
\text { - Archivo fotográfico.Colección 19. Subserie 2: } \\
\text { - ES_FEPP_S5_CVD_S2_00001 a ES_FEPP_S5_CVD_S2_00014. } \\
\text { - Archivo fotográfico.Colección 19.Subserie 3: } \\
\text { - ES_FEPP_S5_CVD_S3_00001 a ES_FEPP_S5_CVD_S3_00022. } \\
\text { - Archivo de planos: ES_FEPP_S6_15_00001 a } \\
\text { - ES_FEPP_S6_15_00010. }\end{array}$ \\
\hline Catalogador & Pérez Belda, Emilio; Pérez Almagro, M. Carmen \\
\hline Cumplimentador & Pérez Almagro, M. Carmen: 2016-12-05 \\
\hline Estado de conservación & Bueno \\
\hline
\end{tabular}

Tabla III. Ejemplo de ficha documental para cada unidad. Serie Vidriera Hipercúbica.

\section{RESULTADOS}

Los resultados alcanzados en esta investigación son de tipo cuantitativos y cualitativos.

La Tabla IV recoge la relación de positivos de las veintiuna series documentales del Archivo Fotográfico del fondo Emilio Pérez Piñero. Las series con un mayor volumen de positivos corresponden a los proyectos: Estructura reticular estérea plegable (1961), Pabellón Transportable para Exposiciones (1964), Teatro Transportable para Festivales de España (1966) y Cúpula desplegable para grandes luces (1968).

\begin{tabular}{|l|l|}
\hline Series documentales de la sección Archivo Fotográfico & $\mathrm{N}^{0}$ imágenes \\
\hline 1. Estructura reticular estérea plegable (1961) & 73 \\
\hline 2. Cúpula rebajada desplegable (1962) & 39 \\
\hline 3. Proyecto Fin de Carrera (1962) & 29 \\
\hline 4. Maqueta de la Ermita de la Estación (1963) & 18 \\
\hline 5. Pabellón Transportable para Exposiciones (1964) la maqueta Vidriera & 486 \\
\hline $\begin{array}{l}\text { 6. Estructura reticular desplegable plana (base de la } \\
\text { Hipercúbica, 1964) }\end{array}$ & \multicolumn{2}{|l|}{} \\
\hline 7. Estructura desplegable plana (1964) & 27 \\
\hline 8. Cúpula reticular desplegable (1962, 1965) & 221 \\
\hline 9. Cúpula reticular poliédrica desmontable (1965-1966) & 90 \\
\hline 10. Teatro Transportable para Festivales de España (1966) & 282 \\
\hline 11. Fila de butacas plegable (1966-1967) & 6 \\
\hline 12. Cúpula reticular transportable y desplegable desde un helicóptero (1966) & 7 \\
\hline 13. Estructura para la sala de proyecciones mediante sistema Cinerama & 30 \\
\hline (1967) & \\
\hline 14. Cúpula reticular desmontable de chapa (1967) & 24 \\
\hline 16. Módulo desplegable automático (1969) & 360 \\
\hline
\end{tabular}




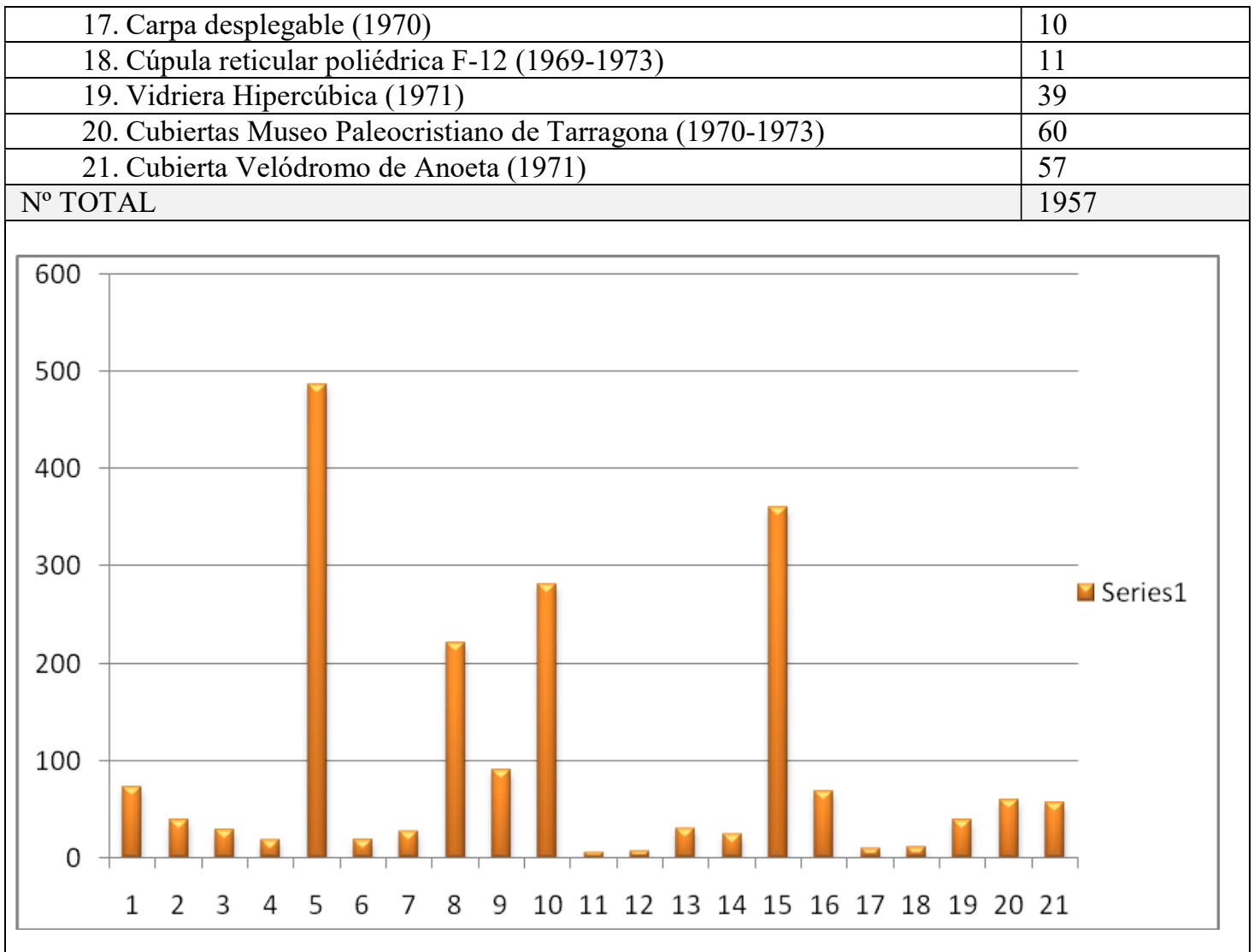

Tabla IV. Relación de positivos fotográficos de las series documentales. Tabla y gráfico.

El proyecto experimental Estructura reticular estérea plegable (serie 1) se trata de la primera maqueta realizada por el arquitecto con motivo del VI Congreso Internacional de la Unión de Arquitectos. Estas imágenes fueron tomadas en la Escuela Superior de Arquitectura de Madrid y en el certamen de Londres, probablemente por los mismos compañeros y profesores de Pérez Piñero. La serie 15: Cúpula desplegable para grandes luces fue íntegramente fotografiada por el arquitecto, en una etapa de experimentación que le llevó a publicar una separata en la revista Arquitectura.

Pabellón Transportable para Exposiciones (serie 5) y Teatro Transportable para Festivales de España (serie 10) corresponden a dos proyectos construidos para el Ministerio de Información y Turismo. La mayoría de las imágenes de estas series son positivos de fotógrafos profesionales que trabajaban para la administración. Ambas obras son dos ejemplos de arquitectura efímera e itinerante de Pérez Piñero. El Pabellón Transportable estuvo expuesto en Madrid, San Sebastián y Barcelona para albergar la exposición conmemorativa $X X V$ Años de Paz, mientras que el Teatro Transportable se empleó como sala para espectáculos folklóricos, siendo A Coruña su primer escenario. Recientemente, el entonces Ministro de Información y Turismo, Manuel Fraga Iribarne, describió al director de la Fundación, Emilio Pérez Belda, qué representó aquella época para la historia de España:

Aquellos momentos eran clave pues desde el Ministerio de Información y Turismo se estaba relanzando el concepto del Turismo, que ayudó a equilibrar la maltrecha balanza de pagos y abrir España al exterior, al tiempo que sentábamos las bases de la Transición, al margen de otras discusiones intelectuales. (ES_FEPP_FEPB_S1_01_00001).

Un ejemplo más de esa propaganda fueron las postales y tarjetas de felicitación que traspasaban las fronteras, mostrando la imagen del progreso del país (Figura 2). 


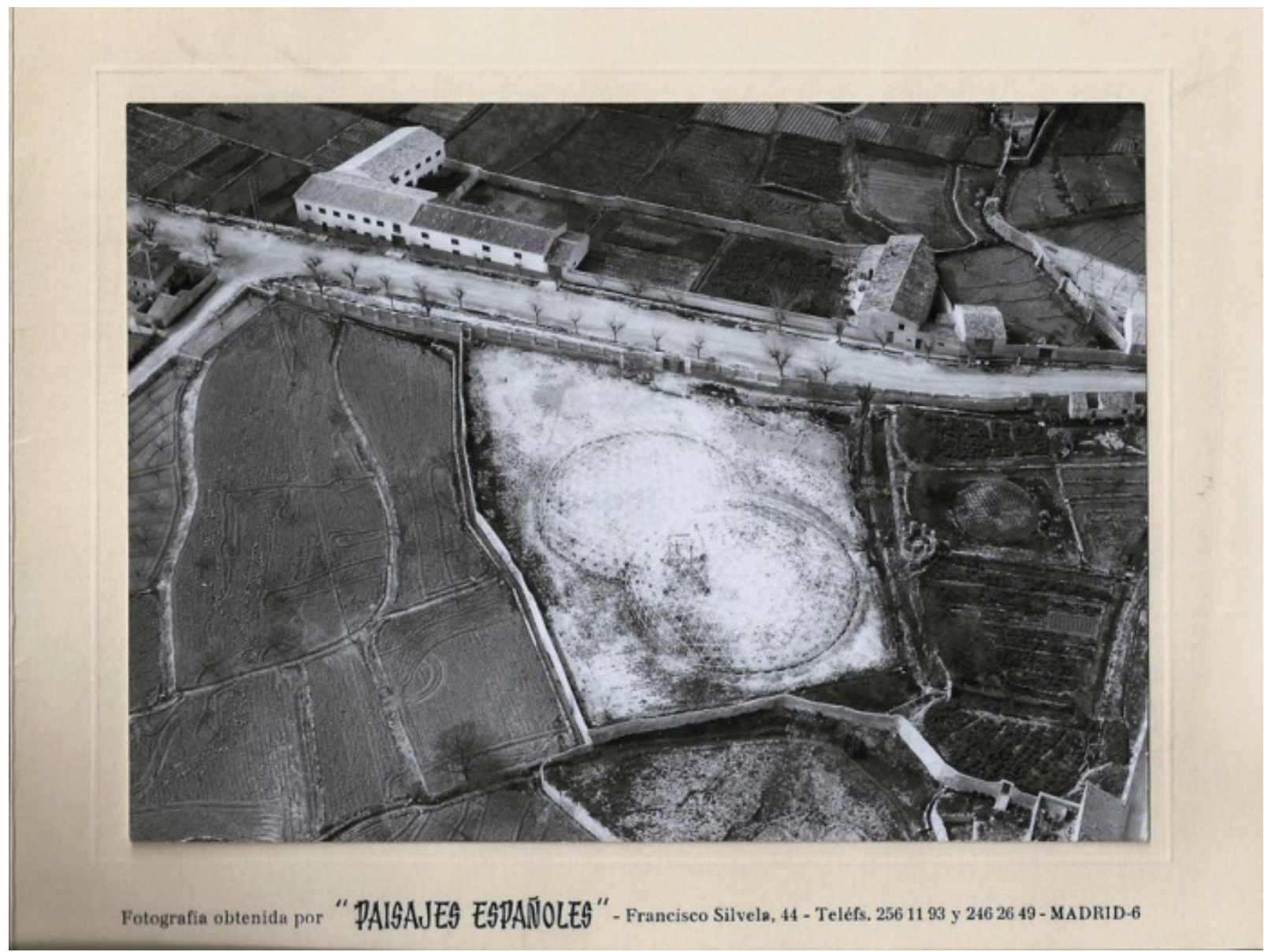

Figura 2. Panorámica aérea del Teatro Transportable para Festivales de España en postal navideña (1965). Fotógrafo Paisajes españoles. ${ }^{\odot}$ Fundación Emilio Pérez Piñero.

La figura y obra de Pérez Piñero tuvo también su repercusión en la prensa de la época. La Tabla V muestra la relación de noticias de prensa por año en los diarios nacionales y locales. Esta información forma parte de la sección documental cuarta del fondo Emilio Pérez Piñero.

\begin{tabular}{|c|c|c|c|c|c|c|c|c|c|c|c|c|}
\hline \multirow{2}{*}{$\begin{array}{rr}\text { DIARIOS } & Y \\
\text { REVISTAS } \\
\end{array}$} & \multicolumn{12}{|c|}{ AÑO } \\
\hline & 1961 & 1962 & 1963 & 1964 & 1965 & 1966 & 1967 & 1968 & 1969 & 1970 & 1971 & 1972 \\
\hline$A B C$ & 4 & 2 & & 7 & & 2 & & & & & 1 & 3 \\
\hline Arriba & 1 & 1 & 1 & 2 & & 1 & & & & & & 1 \\
\hline $\begin{array}{c}\text { Blanco y Negro } \\
\text { (Madrid) }\end{array}$ & & 1 & & 1 & & & & & & & & 1 \\
\hline $\begin{array}{l}\text { Boletín } \\
\text { Información } \\
\text { (Murcia) }\end{array}$ & & & & & & & & & & & & 1 \\
\hline $\begin{array}{l}\text { Dígame. } \\
\quad \text { Rotativo } \\
\quad \text { gráfico } \\
\text { semanal }\end{array}$ & & & & 1 & & & & & & & & \\
\hline $\begin{array}{c}\text { El } \quad \text { Alcázar. } \\
\quad \text { Diario } \\
\text { tradicionalis } \\
\text { ta } \text { (Madrid) }\end{array}$ & 1 & 1 & & & 1 & 1 & & & & & & \\
\hline $\begin{array}{c}\text { El } \begin{array}{c}\text { Correo } \\
\text { Catalán }\end{array} \\
\end{array}$ & 1 & & & & & & & & & & & \\
\hline El Diario Vasco & & & & 2 & & & 1 & & & & & \\
\hline $\begin{array}{ll}\text { El Ideal }\end{array}$ & & & & & & 2 & & & & & & \\
\hline
\end{tabular}




\begin{tabular}{|c|c|c|c|c|c|c|c|c|c|c|c|c|}
\hline \multirow{2}{*}{$\begin{array}{rr}\text { DIARIOS } & Y \\
\text { REVISTAS } \\
\end{array}$} & \multicolumn{12}{|c|}{ AÑO } \\
\hline & 1961 & 1962 & 1963 & 1964 & 1965 & 1966 & 1967 & 1968 & 1969 & 1970 & 1971 & 1972 \\
\hline Gallego & & & & & & & & & & & & \\
\hline $\begin{array}{l}\text { Hoja del Lunes } \\
\text { (La Coruña, } \\
\text { Madrid, } \\
\text { Murcia) }\end{array}$ & 1 & & & 3 & & 1 & 1 & & & & 1 & 3 \\
\hline Informaciones & & & & 1 & & 1 & & & & & & 2 \\
\hline $\begin{array}{l}\text { Informaciones } \\
\text { de la } \\
\text { Ciencia y la } \\
\text { Técnica }\end{array}$ & & & & & & & & & & & & 1 \\
\hline $\begin{array}{l}\text { Jaén. Diario } \\
\text { Provincial } \\
\text { del } \\
\text { Movimiento }\end{array}$ & 1 & & & & & & & & & & & \\
\hline $\begin{array}{c}\text { La Noche de } \\
\text { Galicia. } \\
\text { Diario } \\
\text { vespertino } \\
\text { de Galicia }\end{array}$ & & & & 1 & & 2 & & & & & & \\
\hline $\begin{array}{c}\text { La Vanguardia } \\
\text { Española }\end{array}$ & 2 & & & 2 & & 1 & & & & & & 4 \\
\hline $\begin{array}{l}\text { La Verdad de } \\
\text { Murcia }\end{array}$ & 4 & 2 & & 6 & & 4 & 1 & 1 & & & & 10 \\
\hline La $\begin{array}{c}\text { Voz } \\
\text { Castilla } \\
\text { (Burgos) }\end{array}$ & & 1 & & & & & & & & & & \\
\hline $\begin{array}{c}\text { La Voz de } \\
\text { España (San } \\
\text { Sebastián) }\end{array}$ & & & & 1 & & & 2 & & & & & 1 \\
\hline La $\underset{\text { Galicia }}{\text { Voz }}$ de & & & & & & 2 & & & & & & \\
\hline $\begin{array}{c}\text { Línea. Diario } \\
\text { Regional del } \\
\text { Movimiento } \\
\text { en Murcia }\end{array}$ & 3 & 1 & & 2 & & & & & & & & 6 \\
\hline $\begin{array}{c}\text { Los Sitios. } \\
\text { Diario del } \\
\text { Movimiento } \\
\text { en Gerona }\end{array}$ & & & & & & & & & & & 1 & \\
\hline $\begin{array}{c}\text { Madrid. Diario } \\
\text { de la Noche }\end{array}$ & 4 & 2 & & & & 1 & & & & & & \\
\hline $\begin{array}{l}\text { Noticiero } \\
\text { Universal }\end{array}$ & 1 & & & & & & & & & & & \\
\hline Pueblo & 1 & 2 & & 1 & & 1 & & & & & & \\
\hline $\begin{array}{c}\text { Técnica } \\
\text { Invención }\end{array}$ & 1 & & & & & & & & & & & \\
\hline Tiempo Nuevo & 1 & & & & & & & & & & & \\
\hline $\begin{array}{l}\text { Unidad. Diario } \\
\text { guipuzcoano } \\
\text { de la tarde }\end{array}$ & & & & 1 & & & & & & & & \\
\hline$Y A$ & 3 & 3 & & 6 & 1 & 4 & & & 1 & & & 5 \\
\hline$N^{o}$ TOTAL & 29 & 16 & 1 & 37 & 2 & 23 & 5 & 1 & 1 & 0 & 3 & 38 \\
\hline
\end{tabular}

Tabla V. Relación de noticias en prensa con referencias a Emilio Pérez Piñero (1961-1972).

De las 156 noticias publicadas en prensa, la gran mayoría se concentran entre los años 1961 (18,58\% del total), 1962 (10,45\%), 1964 (24,18\%), $1966(14,74 \%)$ y 1972 (24,83\%), coincidiendo con los proyectos más fotografiados de 
las series documentales y el año de fallecimiento del arquitecto. 63 de las 156 noticias incluían fotografías de Pérez Piñero o de su arquitectura (40,38\%) (Figura 3).

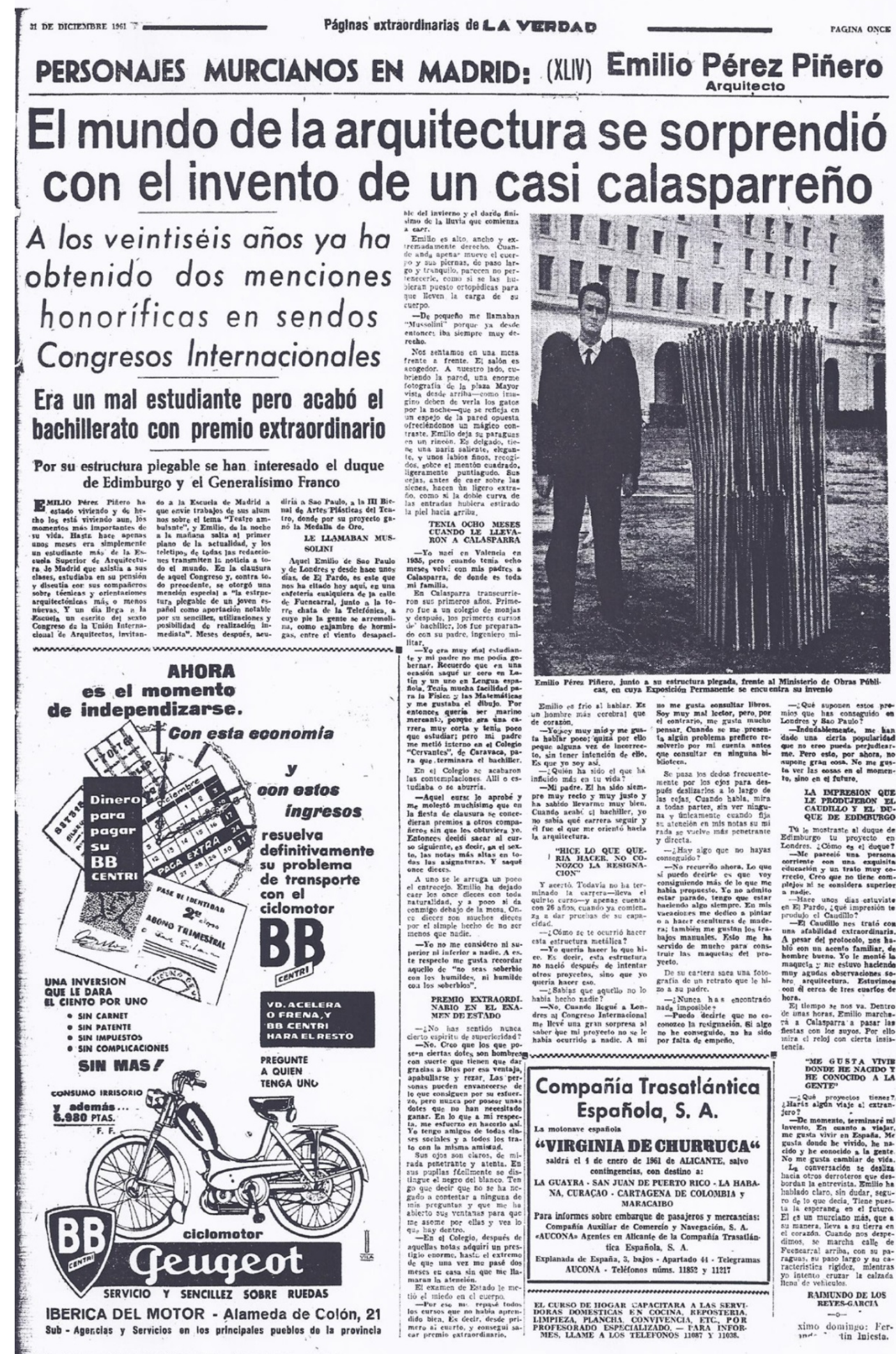

Figura 3. Noticia de prensa sobre Pérez Piñero, La Verdad de Murcia, 31/12/1961, p. 11. 
Las fechas con mayor volumen de noticias en prensa también se repiten entre las publicaciones realizadas por Pérez Piñero en las revistas técnicas más importantes del momento: Índice de Artes y Letras (1961), The Architects' Journal (1961), Architectural Design (1961), Progressive Architecture (1962), Hogar y Arquitectura (1962, 1970), The Student Architect (1962), Building Progress (1963), Arquitectura (1964, 1968, 1972), The Architect \& Building News (1966), L'Architecture d'Aujourd'hui (1968), Nueva Forma (1970) e Informes de la Construcción (1971).

Además de la cuantificación de las imágenes en series documentales, esta investigación sobre el archivo fotográfico aporta resultados de tipo cualitativo, al tratarse el documento fotográfico como objeto de estudio etnográfico. Las reglas de descripción multinivel permiten realizar una descripción de lo general a lo particular con información concreta de cada serie y unidad documental.

Para el fotógrafo que capturó ese instante en una imagen fue un documento técnico que recogía los avances alcanzados por el arquitecto a través de diferentes planos, vistas generales, series del proceso de montaje y fotos de detalle. Sin embargo, en el presente la interpretación fotográfica aporta otras lecturas, en función de las variables utilizadas para el análisis, como son:

- el propio arquitecto

- artesanos de Calasparra que formaban parte de su equipo

- sujetos pasivos observadores de la escena

- personajes públicos coetáneos

- paisaje rural y urbano y

- elementales medios técnicos

En definitiva, el estudio etnográfico que aporta la fotografía reconstruye el contexto socio-cultural y la forma de trabajar de Pérez Piñero. Es un testimonio del grado de implicación del arquitecto en el desarrollo de su obra y en enseñar a sus artesanos el proceso de montaje. Permite conocer el modo de vestir de la época. Se observa la casi ausencia de medidas de protección y seguridad en el trabajo (como actualmente son entendidas). Es innegable que suscitaba interés en el público, que en cierto modo curioso se acercaba expectante, y el impacto visual de estas estructuras futuristas en el paisaje rural y urbano del momento (Figuras: 4-5).

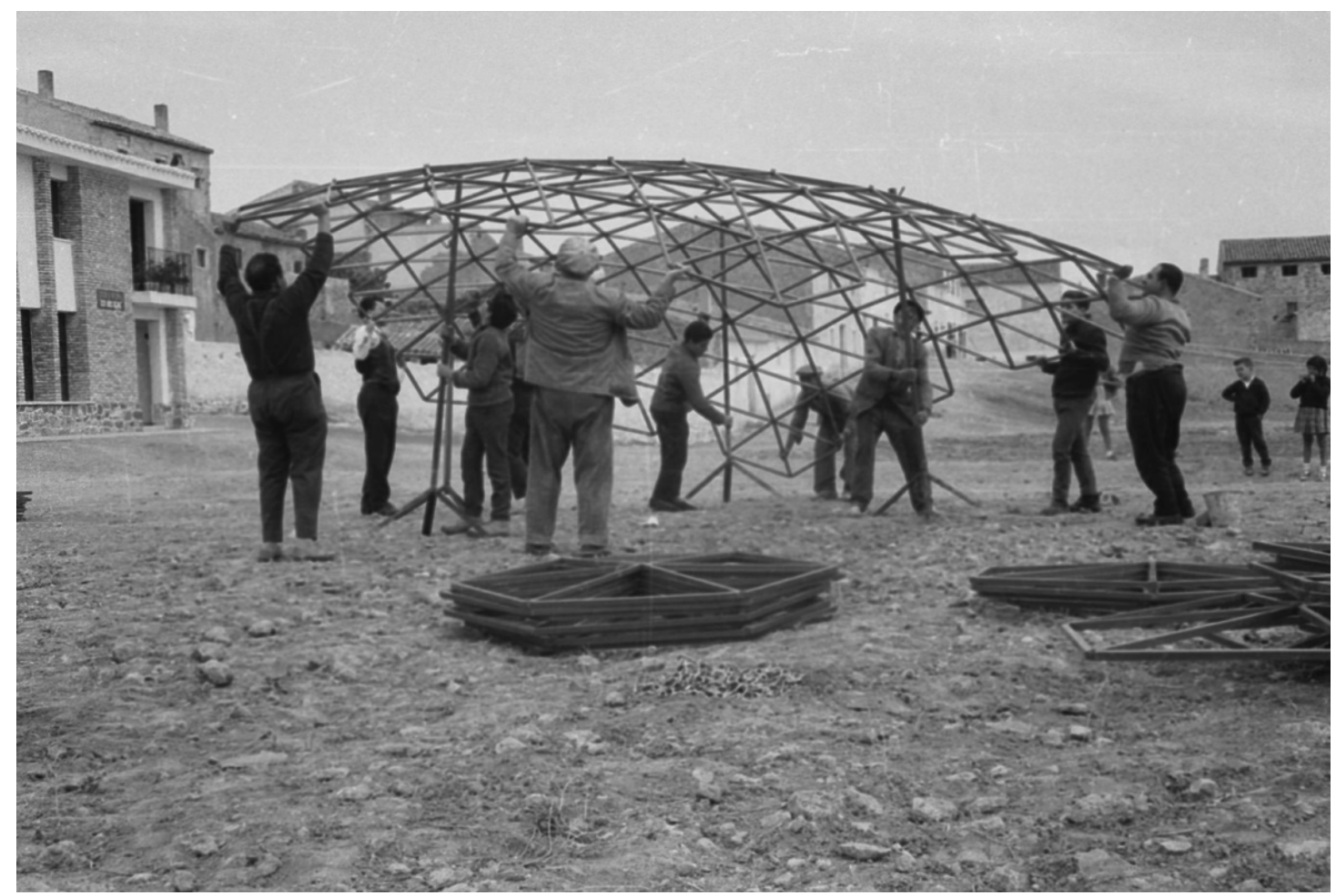

Figura 4. Montaje de la estructura Cúpula rebajada desplegable en Calasparra (1962). C Fundación Emilio Pérez Piñero. 


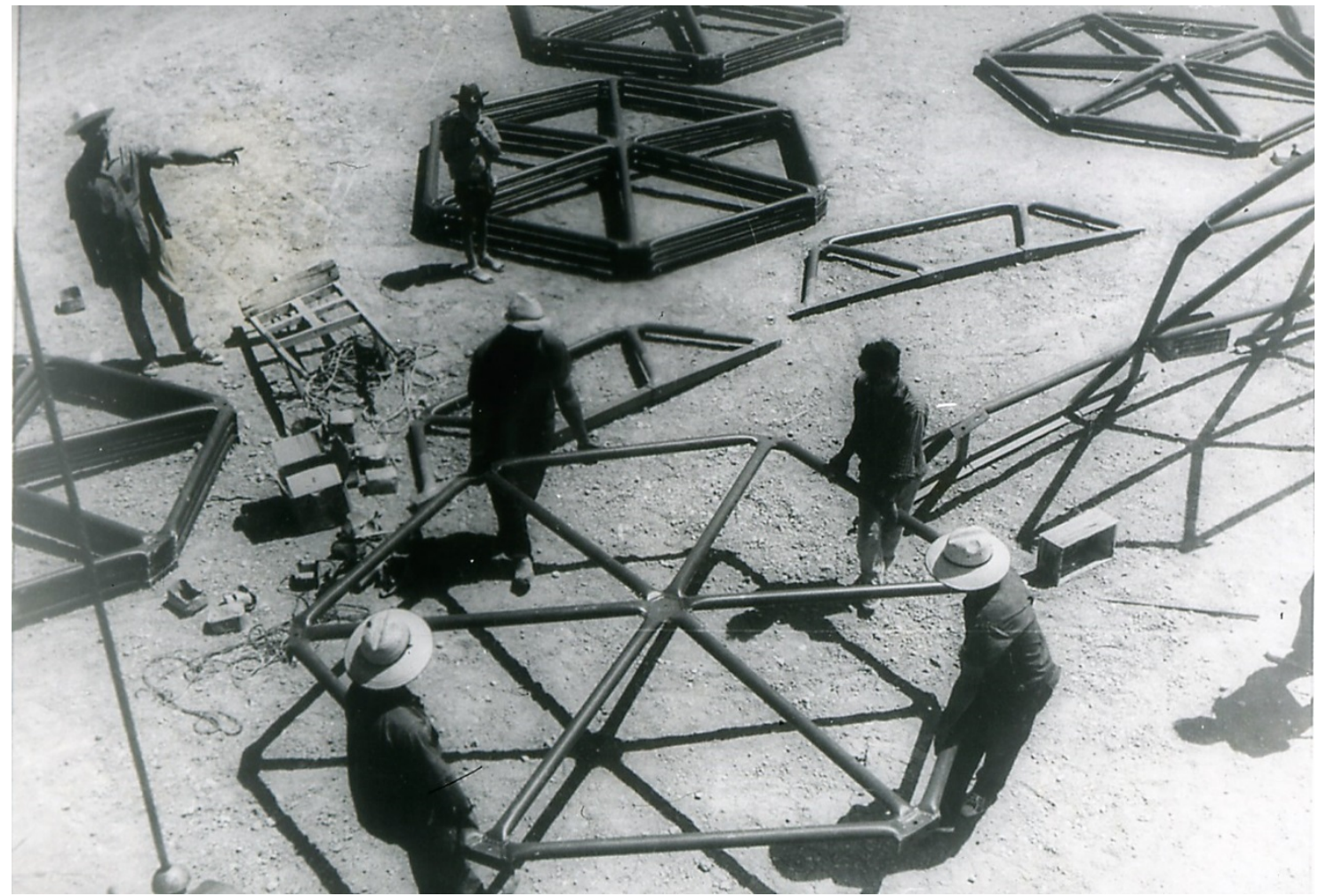

Figura 5. Montaje de prueba del Teatro Transportable para Festivales de España en Calasparra (1966). (C) Fundación Emilio Pérez Piñero.

\section{CONCLUSIONES}

La fotografía tiene un valor intrínseco desde el punto de vista histórico, documental y artístico. Una imagen muestra un instante concreto en un espacio y tiempo determinado, representa una realidad que transmite información de tipo sociocultural y técnico y a su vez es un medio de expresión artística intencionada por parte del autor.

El estudio en profundidad de este Archivo Fotográfico ha permitido describir, analizar e interpretar la relación establecida del arquitecto con el resto de los retratados y el diálogo-ruptura de sus estructuras sobre la geografía física y humana del momento. Este Archivo Fotográfico cumple la función de registro, en su categoría de fotografía científico-técnica y retrato, pero también es un documento informativo, publicitario y artístico (Boadas y otros, 2001, p. 134) que ayuda a reconstruir el contexto, denominado Desarrollismo, de la sociedad española de los años 60 y principios de los 70. Tanto Pérez Piñero como el Gobierno de la época emplearon conscientemente las fotografías para difundir los avances técnicos. El arquitecto pretendía informar de sus logros en revistas especializadas, informes técnicos y prensa; mientras que la Administración Pública mostraba una imagen del progreso del país a través de los medios, con fines propagandísticos.

La importancia de estructurar, clasificar, analizar e interpretar el legado fotográfico del arquitecto radica en la conservación y difusión de las series documentales que en algunos casos son el único testimonio directo de la arquitectura ausente. Finalmente, con esta investigación se ha aportado un método de trabajo para el estudio de conjuntos documentales similares relacionados con la fotografía de arquitectura.

\section{BIBLIOGRAFÍA}

BERGERA, I. (ed.). Fotografía y arquitectura moderna en España, 1925-1965. Madrid: Fundación ICO and La Fábrica, 2014.

BOADAS, J.; CASELLAS, LL.E. y SUQUET, M.A. Manual para la gestión de fondos y colecciones fotográficas. Girona: Curbet comunicació gràfica, 2001.

CARRETERO PÉREZ, A. et al. Normalización documental de museos: elementos para una aplicación informática de gestión museográfica. Madrid: Ministerio de Educación y Cultura, 1996. 
FLORES VARELA, C. Informatización para archivos sin recursos: el Archivo Histórico Provincial de Toledo. XIII International Conference of the Association for History \& Computing, Toledo: Ediciones de la Universidad de Castilla-La Mancha, 1998.

FUSTER RUIZ, F. Archivística, archivo, documento de archivo... Necesidad de clarificar los conceptos. Anales de Documentación, 1999, vol. 2, p. 103-120.

IPCE. Plan Nacional de Conservación del Patrimonio Fotográfico. Madrid: Secretaría General Técnica. Centro de Publicaciones. Ministerio de Educación, Cultura y Deporte, 2016.

ISAD (G). Norma Internacional General para la Descripción Archivística (2 ${ }^{\mathrm{a}}$ ed.), Madrid: Ministerio de Educación, Cultura y Deporte, 2000.

Ley 16/1985, de 25 de junio, de Patrimonio Histórico Español.

MARZAL FELICI, J. Cómo se lee una fotografia: interpretaciones de la mirada. Madrid: Cátedra, 2008.

MCU. Reglas de catalogación (6 ${ }^{\mathrm{a}}$ ed.). Madrid: Secretaría General Técnica, 2006.

OSUNA ARIAS, M.C.; MOLINA NORTES, J. y MARTÍN ALBALADEJO, C. Organización y puesta en valor del fondo documental del Instituto Español de Entomología (archivo histórico del Museo Nacional de Ciencias Naturales, Consejo Superior de Investigaciones Científicas). Revista Española de Documentación Científica, 2016, 39 (3): e144. Disponible en: <http://dx.doi.org/10.3989/redc.2016.3.1287a $>$. [Consulta: 12 de diciembre de 2016].

PÉREZ ALMAGRO M.C. Estudio y normalización de la colección museográfica y del archivo de la Fundación Emilio Pérez Piñero, Tesis doctoral: Universidad de Murcia, 2013.

PÉREZ ALMAGRO, M.C. Emilio Pérez Piñero en SÁEZ GÓMEZ, J.M.; LÓPEZ FERNÁNDEZ, C.; MARSET CAMPOS, P. y LÓPEZ SÁNCHEZ, J.F. Biografía de Emilio Pérez Piñero en Diccionario Biográfico y Bibliográfico de la Ciencia y la Medicina en la Región de Murcia (vol. 2). Murcia: Editum, 2017, p. 1068-1076.

PÉREZ BELDA, E.A. y PÉREZ ALMAGRO, M.C. La arquitectura desplegable conmemora los XXV años de paz. 50 Aniversario del Pabellón de Emilio Pérez Piñero. Expresión Gráfica Arquitectónica, 2016, vol. 21, n 28, p. 146155. Disponible en: <http://dx.doi.org/10.4995/ega.2016.6307>. [Consulta: 12 de marzo de 2017].

Real Decreto Legislativo 1/1996, de 12 de abril, por el que se aprueba el texto refundido de la Ley de Propiedad Intelectual.

RIEGO, B. (ed). Manual para el uso de archivos fotográficos. Fuentes para la investigación y pautas de conservación de fondos documentales fotográficos, Santander Aula de Fotografía de la Universidad de Cantabria y Ministerio de Educación y Cultura, Dirección General del Libro, Archivos y Bibliotecas, 1997.

RIVAS QUINZAÑOS, P.; RUILOPE URIOSTE, B. y SUÁREZ MENÉNDEZ, M. El legado del arquitecto: los archivos de arquitectura en la ETSA de Madrid. Colección textos dispersos, 2012, n 5, p. 10-25.

SÁNCHEZ VIGIL, J.M. y SALVADOR BENÍTEZ, A. Documentación fotográfica. Barcelona: UOC, 2013.

VIVAS MORENO, A. Documentación del Archivo Universitario de Salamanca: análisis descriptivo de sus series documentales. Anales de documentación, 2000, nº 3, p. 167-207.

VV.AA. I Jornadas para la Conservación y Recuperación de la Fotografia. Madrid: Centro Nacional de Información Artística, Arqueológica y Etnológica, 1985. 